\title{
Vero cytotoxin-producing strains of Escherichia coli
}

\author{
H. R. SMITH and SYLVIA M. SCOTLAND
}

Division of Enteric Pathogens, Central Public Health Laboratory, Colindale Avenue, London NW9 5 HT

\section{Discovery and definition}

In 1977 Konowalchuk and colleagues showed that culture filtrates of some strains of Escherichia coli produced a cytotoxic effect on Vero cells, a line of African green-monkey kidney cells. Two other cell lines, Y1 mouse adrenal cells and Chinese hamster ovary cells, were not affected by these filtrates and therefore their activity could be distinguished easily from that of $E$. coli heat-labile enterotoxin. The cytopathic effect on Vero cells was shown to be due to the action of one or more cytotoxins termed Vero cytotoxins (VT). Because seven of the ten Vero cytotoxin-producing strains of $E$. coli (VTEC) were isolated from infants with diarrhoea, it was suggested that VT might be a virulence factor. During the last ten years the study of VTEC has increased dramatically and the role of these organisms in disease is now well established.

The early studies indicated that there might be more than one VT (Konowalchuk et al., 1977) and later experiments have demonstrated this clearly. The VT produced by $E$. coli strain $\mathrm{H} 30$, of serotype O26:H11, was shown to be very similar to Shiga toxin, produced by strains of Shigella dysenteriae of serotype 1, in terms of biological properties, physical characteristics and also antigenicity (O'Brien et al., 1982; O'Brien and LaVeck, 1983). Because of these similarities, the term Shiga-like toxin (SLT) was used to describe such a toxin produced by $E$. coli strains. Both terms, VT and SLT, are widely used. The type of VT neutralised by anti-Shiga toxin was designated VT1 and a second VT, first shown in strains of $E$. coli of serogroup $\mathrm{O} 157$ and which was not neutralised by anti-Shiga toxin, was termed VT2 (Scotland et al., 1985). This subdivision was supported by genetic studies which demonstrated that DNA probes for the VT1 and VT2 genes did not cross-hybridise under stringent conditions (Willshaw et al., 1985, 1987). It is now clear (Yutsudo et al., 1987) that

Received 28 Nov. 1987; accepted 22 Dec. 1987.
VT1 and VT2 are the same as SLTI and SLTII defined by Strockbine et al. (1986). In this review strains of $E$. coli only will be described in detail and in order to avoid confusion the term VT will be used throughout.

\section{Diseases associated with VTEC}

Konowalchuk et al. (1977) first suggested that production of VT might be a virulence factor in diarrhoeal disease. The importance of VTEC in human disease however, has only been clear in the last 6 years since the association was established between VTEC and two diseases of previously unknown aetiology, haemorrhagic colitis $(\mathrm{HC})$ and haemolytic uraemic syndrome (HUS).

Haemorrhagic colitis is characterised by grossly bloody diarrhoea, usually in the absence of pyrexia. It is frequently preceded by abdominal cramps and a watery diarrhoea. Outbreaks of HC caused by VTEC occurred in different areas of the USA in 1982 (Riley et al., 1983) and since then outbreaks and sporadic cases have been reported in several other countries including Canada, Britain and Japan (Johnson et al., 1983; Pai et al., 1984; Itoh et al., 1985; Smith et al., 1987a).

Haemolytic uraemic syndrome is characterised by three features-acute renal failure, microangiopathic haemolytic anaemia and thrombocytopenia (see Levin and Barratt, 1984). HUS occurs in all age groups, but more commonly in infants and young children, and is a major cause of renal failure in childhood. There are two principal subgroups of HUS, typical HUS associated with a prodromal bloody diarrhoea and an atypical form without a diarrhoeal phase. Evidence of family spread and clustering of cases originally suggested that an infective agent was responsible for the typical form of HUS. Cases of infection with $S$. dysenteriae serotype 1 have led to HUS but several other micro-organisms have also been implicated as a cause of HUS. A close association between VTEC and HUS was first reported by Karmali et al. (1983) and studies since then have established 
that VTEC are a major cause of the typical form of HUS (Karmali et al., 1985; Scotland et al., 1988).

It appears that VTEC infection in man may be associated with a range of clinical symptoms from mild, non-bloody diarrhoea to severe manifestations such as HUS. A wide spectrum of illness may occur within a single outbreak; for example, of 34 patients who developed diarrhoea, 14 were hospitalised and 4 died (Ryan et al., 1986). Another serious condition associated with VTEC infection is thrombotic thrombocytopenic purpura in which the clinical features of HUS are accompanied by neurological involvement and fever.

VTEC have also been implicated with disease in animals particularly calves and pigs. VTEC have been isolated from both diseased and healthy cattle but in one study there was a significant association between isolation of VTEC and diarrhoea (Mohammad et al., 1985). VT-producing strains have also been detected in pigs with diarrhoea or oedema disease, a severe and often fatal disorder in weaned pigs (Dobrescu, 1983; Smith et al., 1983).

\section{Epidemiology of VTEC infections}

In North America, VTEC infections associated with $\mathrm{HC}$ and HUS have occurred over a wide geographic area and have affected males and females of all age groups. The majority of VTEC infections are with strains belonging to serogroup 0157 and have been reported in the summer months. Outbreaks with VTEC have occurred in the community, in nursing homes for the elderly, and in daycare centres for young children, with the most severe clinical manifestations usually seen in the paediatric and geriatric populations (Ryan et al., 1986; Spika et al., 1986; Krishnan et al., 1987).

In Britain, cases of HC and HUS associated with VTEC have been investigated during the last 5 years. An outbreak of HC occurred in the summer of 1985 in widely separated areas in East Anglia in which the epidemic strain was of serotype $0157: \mathrm{H} 7$ (Morgan et al., in press). A prospective study of $\mathrm{HC}$ was conducted in England and Wales from Oct. 1985 to Oct. 1986 and the cases were distributed widely throughout the country and were not noticeably related to urban or rural areas. VTEC were detected by DNA probes in $32(39 \%)$ of 83 specimens with coliforms. Thirty of the 32 VTEC belonged to serogroup $\mathrm{O} 157$ confirming the importance of this serogroup as a cause of haemorrhagic colitis in areas other than North America (Smith et al., 1987a). An outbreak of HUS associated with VTEC of serogroup 0157 occurred in the Wolverhampton area in 1983 and followed an increased incidence of HUS in the West Midlands during 1982 and 1983 (Taylor et al., 1986). The association of VTEC and HUS was further demonstrated in a study in the UK of children under 12 years. As in the HC study the patients with detectable VTEC were from many different areas of the UK (Scotland et al., 1988).

It appears that food is the primary source of infection in man. In at least two outbreaks of $\mathrm{HC}$ due to $E$. coli of serogroup $\mathrm{O} 157$, this organism has been isolated from hamburger meat (Riley et al., 1983; Ryan et al., 1986) whilst unpasteurised milk has been responsible for an outbreak of $\mathrm{HC}$ and two sporadic cases of HUS (Martin et al., 1986; Borczyk et al., 1987). E. coli of serotype O157:H7 was isolated from healthy heifers on the farms associated with the cases of HUS and the HC outbreak. Recently, it was reported that three VTproducing strains of $E$. coli of $0157: \mathrm{H} 7$ were isolated from a calf with colibacillosis in 1977 in Argentina (Ørskov et al., 1987). This gave further support to the suggestion that cattle are a reservoir of infection by $E$. coli of serotype $0157: \mathrm{H} 7$ in man. Examination of retail fresh meats and poultry for strains of serotype 0157:H7 showed that these organisms were present in $1.5-3.7 \%$ of samples of beef, pork, poultry and lamb (Doyle and Schoeni, 1987).

A phage-typing scheme for VT-producing strains of $E$. coli of serogroup $\mathrm{O} 157$ has been developed and used in epidemiological investigations of these organisms (Ahmed et al., 1987); 98 strains from Canada or the USA were typable and were assigned to 14 phage types. The phage-typing results of strains from outbreaks and sporadic cases correlated very closely with the epidemiological findings. This technique should prove useful in further studies of infections caused by VTEC of serogroup 0157 in different parts of the world.

\section{Methods of detecting VT and VTEC}

Several methods have been employed for the detection of VTEC infection in cases of diarrhoea, $\mathrm{HC}$ or HUS and they fall into three categories. These are the isolation of VTEC from faecal specimens, demonstration of specific VT in faecal extracts and the presence of antibodies with VTneutralising ability in patients' sera.

The proportion of VTEC in the faecal flora may be low, often less than $1 \%$, so that picking and testing individual colonies may not always detect the presence of VTEC. DNA probes for the VT1 and VT2 genes have been developed (Willshaw et al., 1987) and with these probes used in colony- 
hybridisation tests, several hundred colonies from a faecal specimen can be examined, thereby increasing sensitivity (Smith et al., 1987a; Scotland et al., 1988).

Whereas $95 \%$ of $E$. coli strains are sorbitol fermenters, VTEC of serogroup O157 do not ferment sorbitol rapidly and this test has been used to detect them (Wells et al., 1983). Tests have used a medium containing sorbitol and an $\mathrm{H} 7$ antiserum (Farmer and Davis, 1985) or a sorbitol-MacConkey agar followed by agglutination with an antiserum specific for the O157 O-antigen (March and Ratnam, 1986). This latter technique provides a simple and useful screening method; however, it is limited because VTEC belonging to serogroups other than $\mathrm{O} 157$ will not be detected.

Confirmation of VT production is shown by testing strains for a cytotoxic effect on Vero cells. HeLa cells, which have been used in studies of Shiga toxin, are also susceptible to VT and several laboratories use this cell line. There have been significant differences in the methods of preparing extracts for testing of cytotoxicity. O'Brien et al. (1982) reported that, after growth under conditions of iron limitation, cell extracts of many $E$. coli strains produced by sonication or cell disruption had a cytotoxic effect on HeLa cells that was neutralisable by anti-Shiga toxin. In this study a few strains produced high levels of toxin equivalent to that produced by strains of $S$. dysenteriae of serotype 1, and in these cases cytotoxin could be detected in culture supernates as well as in cell extracts. For other strains, however, the levels of cytotoxin production were often very low and detectable in bacterial lysates only; these strains included some enteropathogenic $E$. coli (EPEC) and also strains from healthy persons and laboratory strains of $E$. coli strain K12.

In our laboratory, filtered supernates from cultures grown in trypticase soy broth are used for testing strains for VT production (Scotland et al., 1980). Neutralisation tests with antisera raised in rabbits against VT1 or VT2 are then performed to demonstrate production of VT1, VT2 or both toxins (Scotland et al., 1985, 1987). Strains gave highest toxin titres after growth for between $12 \mathrm{~h}$ and $16 \mathrm{~h}$, although there was secretion of toxin throughout exponential growth (Chart et al., 1987). For the purpose of detecting VT there was no advantage from growing bacteria under iron restriction or limitation which resulted in poor growth and reduced yields of VT. VT was detected in culture supernates of certain EPEC strains and these strains hybridised with one or both of the VT probes. For other EPEC, which did not hybridise with either probe, VT was not detected in culture supernates although disrupted cell extracts were cytotoxic for Vero and Y1 cells (Smith et al., 1987b; Chart et al., 1987). This cytotoxic effect was not due to VT, which does not act on Y1 cells (Konowalchuk et al., 1977), and any role for this non-specific activity in pathogenesis is uncertain.

The detection of VT in faecal filtrates has provided evidence of VTEC infection in several studies. A method of screening stool cultures for VT has been described (Karmali et al., 1983, 1985) and can be modified by the use of polymyxin B to release VT from colony sweeps (Karmali, 1987). The demonstration of VT1, VT2 or both toxins in faecal filtrates requires specific antisera for neutralisation of cytotoxicity; production of one or both toxins was shown in faecal samples from HUS cases (Scotland et al., 1988).

Evidence for VTEC infection has also been obtained by observing rising levels of VT-neutralising antibodies in patients' sera (Karmali et al., 1983, 1985).

\section{Properties of E. coli strains producing VT}

Studies of the incidence of VTEC in HC and HUS have shown that the most commonly isolated strains belong to serogroup $\mathrm{O} 157$ and they possess flagellar antigen $\mathrm{H} 7$ or are non-motile. Neutralisation and hybridisation tests have subdivided VTEC of serogroup $\mathrm{O} 157$ into three classes, strains producing VT1, or VT2, or both toxins. In all VTproducing strains of serogroup $\mathrm{O} 157$ examined so far in our laboratory there has been complete agreement between results of neutralisation and hybridisation tests. One-hundred and one strains belonging to serogroup $\mathrm{O} 157$ were isolated in the UK from cases of $\mathrm{HC}$ or HUS; only one produced VT1 alone, 68 produced VT2 and 32 strains synthesised both toxins. In neutralisation tests with strains producing VT1 and VT2 there was no neutralisation by anti-Shiga toxin or anti-VT1, whereas partial neutralisation was observed in some cases with anti-VT2. This observation suggested that in some supernates the titres of VT1 and VT2 were similar and in others VT2 titres were higher than those of VT1 (Scotland et al., 1987). Other workers have compared toxin in cell lysates and supernates and concluded that, when both toxins were produced by the same strain, VT1 predominated in cell lysates and VT2 was the more active toxin in supernates (Strockbine et al., 1986).

Adhesion of bacteria to the intestinal mucosa may be an important factor in their pathogenesis and in $E$. coli strains is often mediated by 
serologically distinct fimbrial antigens on the bacterial cell surface. Recently, Karch et al. (1987b) reported that a plasmid in VT-producing strains of serogroup $\mathrm{O} 157$ was necessary for the expression of fimbriae that determined the attachment of small numbers of bacteria to Intestine 407 cells grown in tissue culture. However, studies by Sherman et al. (1987) on the adherence of strains of serotype O157:H7 to Intestine 407 and HEp-2 cells suggested that surface structures other than fimbriae can mediate attachment of these bacteria to epithelial cells. The plasmid, described by $\mathrm{Karch}$ et al. $(1987 b)$, has a mol. wt of c. $60 \times 10^{6}$, and has been detected in VTEC strains of serogroup 0157 of different origins (Johnson et al., 1983; Wells et al., 1983; Scotland et al., 1987). A DNA probe of $3.4 \mathrm{~kb}$ designated CVD419 derived from this plasmid has been evaluated for the detection of VTEC (Levine et al., 1987). The probe detected 106 of 107 VTEC of serogroup 0157 but hybridised with only 55 of 70 VTEC strains belonging to other serogroups.

Plasmid analysis of strains of serogroup $\mathrm{O} 157$ can be used to identify strains in outbreaks and sporadic cases of infection. In addition to the plasmid that may be associated with adhesion the majority of strains in the UK producing VT1 and VT2 carried a plasmid of mol. wt $4.7 \times 10^{6}$ and this encoded colicin D production (Scotland et al., 1987). Strains producing VT2 only did not have a plasmid of this size although other plasmids were sometimes present. Drug resistance in VTEC of serogroup $\mathrm{O} 157$ is uncommon although three drugresistant strains were identified in a survey of $\mathrm{HC}$ cases in England and Wales (Smith et al., 1987a).

VTEC belonging to serogroup $\mathrm{O} 157$ have some characteristic biochemical reactions that are useful for their identification. They do not ferment sorbitol within 1 day and unlike $90 \%$ of strains of $E$. coli they have no $\beta$-glucuronidase activity (see Krishnan et al., 1987). It seems likely that strains of serotypes O157:H7 or O157:H- (i.e., non-motile) are members of one clone that has become widely distributed particularly in the last few years. There are, however, significant differences between individual strains such as the production of VT1 or VT2 or both toxins.

VT-producing strains belonging to several serogroups other than $\mathrm{O} 157$ have been identified from human disease although for most serogroups the numbers are very small; a summary of such strains is shown in the table. Within these serogroups certain $\mathrm{H}$ types only are associated with VT production; for example, only strains of serogroup O26 with flagellar antigen 11 or that are non-motile. $E$. coli strains belonging to the classical enteropath-
Table. Serotypes of VTEC isolated in the UK from cases of human disease

\begin{tabular}{|c|c|}
\hline Disease* & Serotype \\
\hline $\begin{array}{l}\text { Diarrhoea } \uparrow \\
\text { or } \\
\text { haemor- } \\
\text { rhagic } \\
\text { colitis }\end{array}$ & $\begin{array}{l}\mathrm{O} 4: \mathrm{H} 10, \mathrm{O} 26: \mathrm{H} 11, \mathrm{O} 26: \mathrm{H}-, \mathrm{O} 91: \mathrm{H}- \\
\mathrm{O} 103: \mathrm{H} 2, \mathrm{O} 118: \mathrm{H} 12, \mathrm{O} 128 a b: \mathrm{H} 2, \\
\mathrm{O} 128 a b: \mathrm{H} 8, \mathrm{O} 128 a b: \mathrm{H}-, \mathrm{O} 157: \mathrm{H} 7, \mathrm{O} 157: \mathrm{H}- \\
\mathrm{O} 165: \mathrm{H} 25 \text { and } \mathrm{O} ?: \mathrm{H} 8\end{array}$ \\
\hline $\begin{array}{l}\text { Haemolytic } \\
\text { uraemic } \\
\text { syndrome }\end{array}$ & $\begin{array}{l}\mathrm{O} 5: \mathrm{H}-, \mathrm{O} 26: \mathrm{H} 11, \mathrm{O} 55: \mathrm{H} 7, \mathrm{O} 55: \mathrm{H} 10, \\
\mathrm{O} 104: \mathrm{H} 2, \mathrm{O} 105 a c: \mathrm{H} 18, \mathrm{O} 115: \mathrm{H} 10, \\
\mathrm{O} 128 a b: \mathrm{H} 2, \mathrm{O} 128 a b: \mathrm{H} 25, \mathrm{O} 145: \mathrm{H} 25, \\
\mathrm{O} 153: \mathrm{H} 25, \mathrm{O} 157: \mathrm{H} 7, \mathrm{O} 157: \mathrm{H}-, \mathrm{O} 163: \mathrm{H} 19, \\
\text { O165:H19, O165:H25, O?:H25 and } \\
\text { O rough:H51 }\end{array}$ \\
\hline
\end{tabular}

*Data from Division of Enteric Pathogens, Colindale, London. + The information on the clinical symptoms for many of the patients with diarrhoea was incomplete.

ogenic serogroups have been examined by Verocell tests and DNA hybridisation; VT production and presence of VT genes was limited to a minority of the strains (Scotland et al., 1980; Karch et al., 1987a; Smith et al., 1987b). In these studies VTEC belonging to serogroups O26, O55, O111, O119, O127 and O128 were detected. Many EPEC strains can attach closely to the microvilli of the small intestine and cause effacement of the villus tips. The adhesion of these EPEC strains can be demonstrated in vitro by their adhesion to HEp-2 cells in a "localised" manner and this property is associated with the ability to cause diarrhoea in volunteer studies (reviewed by Levine, 1987). A few strains belonging to serogroups O55, O111, O119 and 0127 showed HEp-2 adhesion together with VT production at a high level (Karch et al., $1987 a$; Levine et al., 1987).

VTEC of serogroups other than 0157 showed hybridisation with the VT1 probe or the VT2 probe or both probes: strains hybridising with the VT2 probe alone were the most frequently isolated. It is interesting that several VTEC not belonging to serogroup $\mathrm{O} 157$ were from HUS patients and only rarely from $\mathrm{HC}$ cases in the UK (Smith et al., 1987a; Scotland et al., 1988). Studies in North America over a 3-year period showed that a small minority of VTEC, isolated from cases of haemorrhagic colitis, belonged to eight serogroups other than 0157 (Bopp et al., 1987). Strains of serogroup $\mathrm{O} 128$ gave heterogeneous results in the probe tests: most hybridised with both VT probes, others with the VT1 probe or the VT2 probe and one strain produced VT but did not hybridise with the probes 
(Smith et al., 1987b). Further studies are required to examine the cytotoxin produced by this strain and its toxin genes.

VTEC isolated from animals belong to a large number of different serogroups (Smith et al., 1983; Mohammad et al., 1986; Smith et al., 1988). We have examined strains isolated in the UK or Asia from pigs and cattle with diarrhoea or from pigs with oedema disease. Vero cytotoxins and VT genes of these animal strains could be identified with antisera and DNA probes developed from VTEC of human origin (Smith et al., 1988). Most of the animal VTEC belonged to serogroups not usually associated with VTEC of human origin, the exceptions being strains of serogroups $\mathrm{O} 5, \mathrm{O} 26$, $\mathrm{O} 55, \mathrm{O} 111$ and $\mathrm{O} 153$ that have been isolated from both human and bovine infections. However, apart from strains from serogroups $\mathrm{O} 26$ and $\mathrm{O} 111$, the human and animal strains differed in the type of VT produced. The bovine strains examined in our survey produced VT1 or VT2 but not both toxins and the levels of toxin production resembled those of strains of human origin. In contrast, the porcine strains hybridised with the VT2 probe only and in all strains cytotoxin production, neutralisable by anti-VT2, was at a low level with titres $\leqslant 160$. The significance of the low level of toxin production in porcine strains is unclear. The cytotoxin in culture filtrates of porcine strains was active on Vero cells but not HeLa cells and appears to be a variant of VT2 (Marques et al., 1987).

\section{Toxin structure, function and mode of action}

Both VT1 and VT2 have been purified to homogeneity and, like Shiga toxin, both VTs are made up of A and B subunits (Yutsudo et al., 1987; reviewed by O'Brien and Holmes, 1987). Based on the translated nucleotide sequences the mol. wts of the VT1 A and B subunits have been calculated as c. 32210 and 7690 ; both subunits are synthesised with signal peptides (Calderwood et al., 1987; Jackson et al., 1987b). The amino-acid sequence of the B subunit of Shiga toxin was identical to the deduced amino-acid sequence of VT1-B (Seidah $e t$ al., 1986). The mol. wts of the A and B subunits of VT2, deduced from the translated nucleotide sequences, were 33135 and 7187 , respectively (Jackson et al., 1987a). Yutsudoet al. (1987) purified VT2 from an 0157 strain and reported the mol. wts for A and B subunits as 35000 and 10700 , respectively; these values corresponded more closely to the predicted values for the unprocessed forms of the VT2 subunits. Further studies should show whether the A and B subunits of VT2 undergo proteolytic processing, like Shiga toxin and VT1, before they are incorporated into the mature holotoxin.

For both toxins the A subunit possesses the biological activity of the toxin whereas the $B$ subunits are thought to mediate specific binding and receptor-mediated uptake of the toxin. VT1 and VT2 have the same biological activities as Shiga toxin: cytotoxicity for Vero and HeLa cells, enterotoxicity in ligated rabbit-gut loops and mouse-paralytic lethality (O'Brien and Holmes, 1987). The toxins can inactivate catalytically the $60 \mathrm{~S}$ ribosomes in toxin-sensitive cells that possess a specific receptor. The receptor for VT1 and VT2 has been identified and is the same as for Shiga toxin; it is a globotriosyl ceramide containing a galactose- $\alpha-(1 \rightarrow 4)$-galactose- $\beta$ - $(1 \rightarrow 4)$-glucose ceramide (Lindberg et al., 1987; Lingwood et al., 1987).

\section{Genetics of VT production}

The genes controlling production of VT are phage-encoded in several $E$. coli strains. This was first demonstrated in strain $\mathrm{H} 19$, of serotype O26:H11 (Scotland et al., 1983; Smith et al., 1983). VT phages have also been detected in strains of serogroups O111, O119, O128 and O157 (Smith et al., 1983; O'Brien et al., 1984; Smith et al., 1984; Karch et al., 1987a; Willshaw et al., 1987). VT production in porcine strains, however, does not appear to be phage mediated and the genes may be located on the chromosome (Smith et al., 1983; Marques et al., 1987). The VT phages could be divided into two types morphologically (figure): those with elongated hexagonal heads and noncontractile flexible tails and those with regular hexagonal heads and shorter contractile tails (Willshaw et al., 1987; P. J. G. M. Rietra, G. A. Willshaw, H. R. Smith, S. M. Scotland, A. M. Field and $B$. Rowe, unpublished results). Phage particles found in strain $\mathrm{H} 19$ belonged to the first group whereas phages found in strains of serogroup $\mathrm{O} 157$ were of the second type. Strains of serogroup O26 produced VT1 only whereas strains of serogroup O157 produced VT1, VT2 or both toxins. In strains of serogroup 0157 producing both VT1 and VT2, two different phages encoded VT1 and VT2, respectively (Strockbine et al., 1986; Willshaw et al., 1987). A VT1-encoding phage from strain 933, of serotype $\mathrm{O} 157: \mathrm{H} 7$ (designated 933J phage) was reported by O'Brien et al. (1984) to be virtually identical to the VT1-encoding phage from strain $\mathrm{H} 19$ (phage H19J) in phage morphology, restriction enzyme-digest pattern and phage polypeptides. 

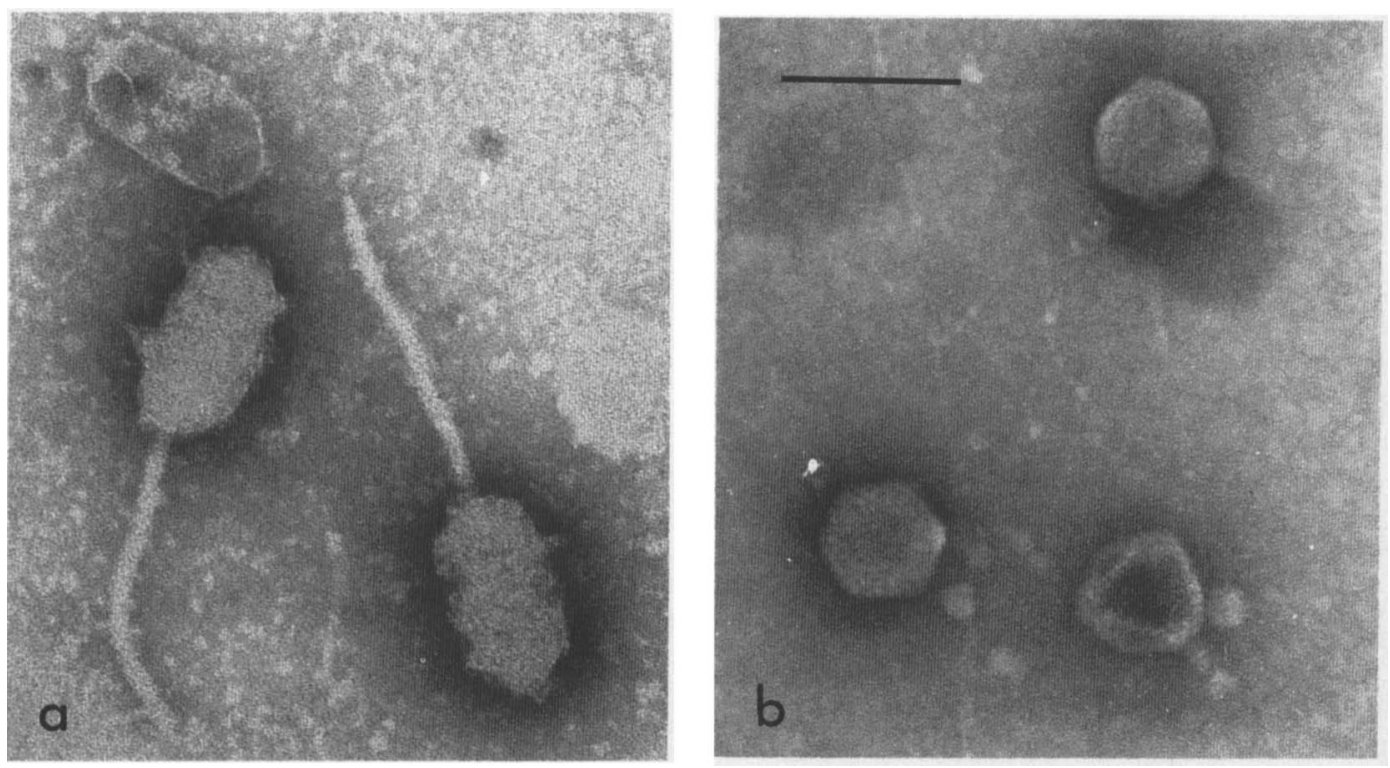

Figure. Electronmicrographs of VT phages from (a) E. coli strain H19 (serotype O26:H11) and (b) E. coli strain E30480 (serotype O157:H7). Both phages code for production of VT1. For details of preparation, see Willshaw et al. (1978). These electronmicrographs are reproduced by kind permission of the Journal of General Microbiology. Bar $=100 \mathrm{~nm}$

However, studies in our laboratory showed that phages encoding VT1 or VT2 in 0157 strains, including 933, were morphologically indistinguishable, similar in genome size and restriction-enzyme digests. They were clearly different in these respects from a VT1-encoding phage from strain $\mathrm{H} 19$, probably identical to phage H19J (Willshaw et al., 1987; P. J. G. M. Rietra et al., unpublished results).

VT genes have been cloned in $E$. coli strain K12 from phages originating in strains of serogroups O26 and O157 (Newland et al., 1985; Willshaw et al., 1985, 1987; Huang et al., 1986). The VT1 region cloned from a strain of serogroup $\mathrm{O} 157$ was very similar to the VT1 sequences cloned from strain $\mathrm{H} 19$ in the distribution of sites for several restriction enzymes. Comparison of these VT1 clones with a fragment encoding VT2 cloned from a phage in strain E32511 from serogroup 0157 showed there were no similarities in the presence of restrictionenzyme sites over a distance of more than $2 \mathrm{~kb}$ containing VT genes. In the flanking sequences of this $2-\mathrm{kb}$ region, however, there were similarities between VT1 and VT2 clones from two 0157 phages (Willshaw et al., 1987). Transposon mutagenesis was used to localise the VT sequences in the VT1 and VT2 clones and in this way probes for the VT genes were developed. Under "stringent" conditions for hybridisation and washing, the VT1 and VT2 probes did not cross-hybridise but under conditions of "reduced" stringency there was weak hybridisation. Thus, these results indicated that the VT1 and VT2 genes were related but not closely homologous (Willshaw et al., 1985, 1987).

The complete DNA sequences for the VT1 and VT2 genes and the regulatory elements have been reported recently (Calderwood et al., 1987; Jackson et al., 1987a,b). The structural genes for VT1 and VT2 shared $58 \%$ overall nucleotide-sequence homology. For both the A and B subunits of VT1 and VT2 the nucleotide and amino-acid sequence homologies varied from 55 to $60 \%$ but there were localised regions of much lower, or much greater, homology. The lowest homologies were found in the signal peptides and the carboxy ends of the A and $B$ subunits. The organisation of the VT1 and VT2 operons was similar and the A and B subunit genes appeared to be translated independently (Jackson et al., 1987a).

\section{Methods for studying VTEC infections}

A number of animal models, including chicks, mice, rabbits, calves and pigs, has been used to study the pathogenesis of VTEC infections. Several studies have examined strains of serotype $\mathrm{O} 157: \mathrm{H} 7$ in gnotobiotic piglets (Francis et al., 1986; Tzipori et al., 1986). The bacteria had an attaching-andeffacing effect on microvilli similar to that seen 
with EPEC in animal models although, unlike EPEC, strains of serogroup O157 proliferated in the lamina propria after destruction of the surface epithelium. The VTEC strains colonised the caecum and colon only whereas EPEC attached to the entire intestine in piglets. Gnotobiotic pigs infected with strains of serotype O157:H7 developed lethargy, watery diarrhoea and anorexia and there was oedema of the colonic mesentery. The clinical features of these $(\mathrm{O} 157)$ infections were similar to those observed in man except that frank blood was seen in the human faeces. Studies with gnotobiotic calves challenged with a VT-producing strain of serogroup $\mathrm{O} 5$ showed that the organisms caused attachment-and-effacement lesions in the ileum and large intestine (Moxley and Francis, 1986).

Smith et al. (1983) examined the effect in pigs of extracts of VT-producing derivatives of $E$. coli strain $\mathrm{K} 12$. Ten of 14 pigs developed clinical signs of oedema disease and it was suggested that VT may be important in this disease. It has now been shown that porcine strains, including some from cases of oedema disease, produced VT2 or a variant of this toxin (Marques et al., 1987; Smith et al., 1988). Purified preparations of VT1 and VT2 caused paralysis and death in mice after intraperitoneal injection (see O'Brien and Holmes, 1987).

Recently human umbilical-cord endothelial cells have been used to study the action of VT1 (Obrig et al., 1987). VT1 had a direct and dose-dependent cytotoxic effect on these cells in culture with actively dividing cells being most sensitive. Since a characteristic renal lesion in HUS is a microangiopathy of the capillaries, the results with this model support the hypothesis that vascular endothelial cells are a primary target for VT.

\section{Concluding remarks}

This brief review shows how the knowledge of VTEC and their importance in human and animal disease has advanced very rapidly in the last 5 years. There are, however, still many unanswered questions and also a need for improvements in methods of detection of VTEC.

Comparisons of VTEC of human and animal origin have provided several interesting observations. VTEC of serogroup O157 are clearly the most important in human disease whereas these strains have usually been isolated from healthy, rather than diseased, animals and have been detected in a range of foods, particularly raw meats. However, experiments have shown that O157 VTEC can cause disease in a range of animal models. VTEC strains belonging to serogroups other than $\mathrm{O} 157$ appear to be isolated quite frequently from cattle and pigs and there is a significant association with disease. In many cases the serogroups of these animal VTEC differ from those of VTEC associated with human disease. Some VTEC from animals may also produce heat-stable or heat-labile enterotoxins whereas, so far, VTEC of human origin have not produced enterotoxins. The production of both cytotoxin and enterotoxin may well affect the clinical symptoms observed in the animal hosts. The differences in biological activity and genetic control of VT in porcine strains compared with human and bovine strains may be important in explaining why VT production by porcine strains is much lower, in general, from that observed with other VTEC.

Further understanding of the Vero cytotoxins from different origins should result from analysis at the amino-acid or nucleotide level. This will provide information on the structure and functions of different regions of the toxin molecules. Sequence data have also produced interesting suggestions about the evolution of bacteria and Vero cytotoxins. Jackson et al. (1987a) proposed that the structural genes for VT1 and VT2 diverged from a common ancestral gene before the evolution of $E$. coli and $S$. dysenteriae serotype 1 as separate genera. Comparison of sequence data showed that the A subunit of VT1 had homology with the A subunit of ricin, a toxin from the castor-bean plant (Calderwood et al., 1987). The two toxins share similar mechanisms of activity on eukaryotic cells and the homology may represent conservation of an active site in the two molecules. The presence of cytotoxins related to VT1 or VT2 in bacteria other than Shigella and $E$. coli has also been investigated (see O'Brien and Holmes, 1987).

There is still much to learn about the precise role of VT in disease. The wide range of clinical symptoms associated with VTEC infections in man and animals suggests there are differences in the response of the host. For example, neurological disorders but not bloody diarrhoea are characteristic of oedema disease in piglets. In addition to the role of VT, the mechanisms of adhesion of VTEC in the early stages of pathogenesis are unclear at present. The association of fimbriae or other surface structures with adhesion is being investigated and will require improved in-vitro techniques as well as the use of animal models.

A variety of methods for detecting VTEC has been described but rapid, simple tests suitable for clinical laboratories are needed. Immunological techniques with ELISAs or latex-particle agglutination should provide convenient tests for these 
laboratories. For large-scale epidemiological surveys, the use of DNA probes may prove to be appropriate. These types of study should lead to a better understanding of the sources and vehicles of VTEC infection.

In July 1987 the first International Symposium

\section{REFERENCES}

Ahmed R, Bopp C, Borczyk A, Kasatiya S 1987 Phage-typing scheme for Escherichia coli O157:H7. Journal of Infectious Diseases 155: 806-809.

Bopp C A, Greene K D, Downes F P, Sowers E G, Wells J G, Wachsmuth I K 1987 Unusual verotoxin-producing Escherichia coli associated with hemorrhagic colitis. Journal of Clinical Microbiology 25 : 1486-1489.

Borczyk A A, Karmali M A, Lior H, Duncan L M C 1987 Bovine reservoir for Verotoxin-producing Escherichia coli 0157:H7. Lancet 1: 98.

Calderwood S B, Auclair F, Donohue-Rolfe A, Keusch G T, Mekalanos J J 1987 Nucleotide sequence of the Shiga-like toxin genes of Escherichia coli. Proceedings of the National Academy of Sciences of the USA 84: 4364-4368.

Chart H, Scotland S M, Rowe B 1987 Production of Vero cytotoxin by strains of Escherichia coli as related to the availability of iron. FEMS Microbiology Letters 48: 385390.

Dobrescu L 1983 New biological effect of edema disease principle (Escherichia coli neurotoxin) and its use as an in vitro assay for this toxin. American Journal of Veterinary Research 44: 31-34.

Doyle M P, Schoeni J L 1987 Isolation of Escherichia coli 0157:H7 from retail fresh meats and poultry. Applied and Environmental Microbiology 53: 2394-2396.

Farmer J J, Davis B R 1985 H7 antiserum-sorbitol fermentation medium: a single tube screening medium for detecting Escherichia coli $0157: \mathrm{H} 7$ associated with hemorrhagic colitis. Journal of Clinical Microbiology 22: 620-625.

Francis D H, Collins J E, Duimstra J R 1986 Infection of gnotobiotic pigs with an Escherichia coli $\mathrm{O} 157: \mathrm{H} 7$ strain associated with an outbreak of hemorrhagic colitis. Infection and Immunity 51: 953-956.

Huang A et al. 1986 Cloning and expression of the genes specifying Shiga-like toxin production in Escherichia coli H19. Journal of Bacteriology 166: 375-379.

Itoh $\mathrm{T}$ et al. 1985 Epidemiological and laboratory investigation of an outbreak of acute enteritis associated with cytotoxinproducing Escherichia coli O145: H-. Annual Report of Tokyo Metropolitan Research Laboratory for Public Health 36: 1622.

Jackson M P, Neill R J, O'Brien A D, Holmes R K, Newland J W 1987a Nucleotide sequence analysis and comparison of the structural genes for Shiga-like toxin I and Shiga-like toxin II encoded by bacteriophages from Escherichia coli 933. FEMS Microbiology Letters 44: 109-114.

Jackson M P, Newland J W, Holmes R K, O'Brien A D $1987 b$ Nucleotide sequence analysis of the structural genes for Shiga-like toxin I encoded by bacteriophage $933 \mathrm{~J}$ from Escherichia coli. Microbial Pathogenesis 2 : 147-153.

Johnson W M, Lior H, Bezanson G S 1983 Cytotoxic Escherichia coli $0157: \mathrm{H} 7$ associated with haemorrhagic colitis in Canada. Lancet 1 : 76.

Karch H, Heesemann J, Laufs R 1987a Phage-associated cytotoxin production by and enteroadhesiveness of entero- on VTEC infections was held in Toronto, Canada; this meeting reflected the great interest in the subject in many countries of the world. It is hoped that some of the knowledge of these organisms can be applied to the prevention and treatment of VTEC infections in man and animals.

pathogenic Escherichia coli isolated from infants with diarrhea in West Germany. Journal of Infectious Diseases 155: 707-715.

Karch H, Heesemann J, Laufs R, O'Brien A D, Tacket C O, Levine M M $1987 b$ A plasmid of enterohemorrhagic Escherichia coli $\mathrm{O} 157: \mathrm{H} 7$ is required for expression of a new fimbrial antigen and for adhesion to epithelial cells. Infection and Immunity 55: 455-461.

Karmali M A 1987 Laboratory diagnosis of verotoxin-producing Escherichia coli infections. Clinical Microbiology Newsletter 9: 65-70.

Karmali M A, Petric M, Lim C, Fleming P C, Arbus G S, Lior H 1985 The association between idiopathic hemolytic uremic syndrome and infection by Verotoxin-producing Escherichia coli. Journal of Infectious Diseases 151 : 775-782.

Karmali M A, Steele B T, Petric M, Lim C 1983 Sporadic cases of haemolytic-uraemic syndrome associated with faecal cytotoxin and cytotoxin-producing Escherichia coli in stools. Lancet 1: 619-620.

Konowalchuk J, Speirs J I, Stavric S 1977 Vero response to a cytotoxin of Escherichia coli. Infection and Immunity 18: 775-779.

Krishnan C, Fitzgerald V A, Dakin S J, Behme R J 1987 Laboratory investigation of outbreak of hemorrhagic colitis caused by Escherichia coli 0157:H7. Journal of Clinical Microbiology 25: 1043-1047.

Levin M, Barratt J M 1984 Haemolytic uraemic syndrome. Archives of Disease in Childhood 59: 397-400.

Levine M M 1987 Escherichia coli that cause diarrhea: enterotoxigenic, enteropathogenic, enteroinvasive, enterohemorrhagic, and enteroadherent. Journal of Infectious Diseases 155: 377-389.

Levine M M et al. 1987 A DNA probe to identify enterohemorrhagic Escherichia coli of O157:H7 and other serotypes that cause hemorrhagic colitis and hemolytic uremic syndrome. Journal of Infectious Diseases 156: 175-182.

Lindberg A A, Brown J E, Stromberg N, Westling-Ryd M, Schultz J E, Karlsson K-A 1987 Identification of the carbohydrate receptor for Shiga toxin produced by Shigella dysenteriae type 1. Journal of Biological Chemistry 262: 1779-1785.

Lingwood C A et al. 1987 Glycolipid binding of purified and recombinant Escherichia coli produced verotoxin in vitro. Journal of Biological Chemistry 262: 8834-8839.

March S B, Ratnam S 1986 Sorbitol-MacConkey medium for detection of Escherichia coli 0157:H7 associated with hemorrhagic colitis. Journal of Clinical Microbiology 23: 869-872.

Marques L R M, Peiris J S M, Cryz S J, O’Brien A D 1987 Escherichia coli strains isolated from pigs with edema disease produce a variant of Shiga-like toxin II. FEMS Microbiology Letters 44: 33-38.

Martin M L et al. 1986 Isolation of Escherichia coli 0157:H7 from dairy cattle associated with two cases of haemolytic uraemic syndrome. Lancet 2: 1043.

Mohammad A, Peiris J S M, Wijewanta E A, Mahalingam S, Gunosekera G 1985 Role of verotoxigenic Escherichia coli 
in cattle and buffalo calf diarrhoea. FEMS Microbiology Letters 26: 281-283.

Mohammad A, Peiris J S M, Wijewanta E A 1986 Serotypes of verocytotoxigenic Escherichia coli isolated from cattle and buffalo calf diarrhoea. FEMS Microbiology Letters 35 : 261265.

Morgan G M et al. A community outbreak of haemorrhagic colitis due to Verotoxin producing Escherichia coliO157:H7. Epidemiology and Infection, in press.

Moxley R A, Francis D H 1986 Natural and experimental infection with an attaching and effacing strain of Escherichia coli in calves. Infection and Immunity 53: 339-346.

Newland J W, Strockbine N A, Miller S F, O'Brien A D, Holmes R K 1985 Cloning of Shiga-like toxin structural genes from a toxin converting phage of Escherichia coli. Science 230: 179-181.

O’Brien A D, LaVeck G D 1983 Purification and characterization of a Shigella dysenteriae 1-like toxin produced by Escherichia coli. Infection and Immunity 40: 675-683.

O'Brien A D, Holmes R K 1987 Shiga and Shiga-like toxins. Microbiological Reviews 51: 206-220.

O'Brien A D, LaVeck G D, Thompson M R, Formal S B 1982 Production of Shigella dysenteriae type 1-like cytotoxin by Escherichia coli. Journal of Infectious Diseases 146: 763-769.

O'Brien A D, Newland J W, Miller S F, Holmes R K, Smith H W, Formal S B 1984 Shiga-like toxin-converting phages from Escherichia coli strains that cause haemorrhagic colitis or infantile diarrhea. Science 226: 694-696.

Obrig T G, Del Vecchio P J, Karmali M A, Petric M, Moran T P, Judge T K 1987 Pathogenesis of haemolytic uraemic syndrome. Lancet $2: 687$.

Ørskov F, Ørskov I, Villar J A 1987 Cattle as reservoir of Verotoxin-producing Escherichia coli O157:H7. Lancet 2: 276.

Pai C H, Gordon R, Sims H V, Bryan L E 1984 Sporadic cases of hemorrhagic colitis associated with Escherichia coli O157:H7. Clinical, epidemiologic, and bacteriologic features. Annals of Internal Medicine 101 : 738-742.

Riley L W et al. 1983 Hemorrhagic colitis associated with a rare Escherichia coli serotype. New England Journal of Medicine 308: 681-685.

Ryan C A et al. 1986 Escherichia coli O157:H7 diarrhea in a nursing home: clinical epidemiological, and pathological findings. Journal of Infectious Diseases 154: 631-638.

Scotland S M, Day N P, Rowe B 1980 Production of a cytotoxin affecting Vero cells by strains of Escherichia coli belonging to traditional enteropathogenic serogroups. FEMS Microbiology Letters 7 : 15-17.

Scotland S M, Rowe B, Smith H R, Willshaw G A, Gross R J 1988 Vero cytotoxin-producing strains of Escherichia coli from children with haemolytic uraemic syndrome and their detection by specific DNA probes. Journal of Medical Microbiology 25: 237-243.

Scotland S M, Smith H R, Rowe B 1985 Two distinct toxins active on Vero cells from Escherichia coli O157. Lancet 2: 885-886.

Scotland S M, Smith H R, Willshaw G A, Rowe B 1983 Vero cytotoxin production in strain of Escherichia coli is determined by genes carried on bacteriophage. Lancet 2: 216 .

Scotland S M, Willshaw G A, Smith H R, Rowe B 1987 Properties of strains of Escherichia coli belonging to serogroup 0157 with special reference to production of Vero cytotoxins VT1 and VT2. Epidemiology and Infection 99: 613-624.

Seidah N G, Donohue-Rolfe A, Lazure C, Auclair F, Keusch G T, Chretien M 1986 Complete amino acid sequence of Shigella toxin B-chain. A novel polypeptide containing 69 amino acids and one disulfide bridge. Journal of Biological Chemistry 261 : 13928-13931

Sherman P, Soni R, Petric M, Karmali M 1987 Surface properties of the Vero cytotoxin-producing Escherichia coli O157:H7. Infection and Immunity 55: 1824-1829.

Smith H R, Day N P, Scotland S M, Gross R J, Rowe B 1984 Phage-determined production of Vero cytotoxin in strains of Escherichia coli serogroup O157. Lancet 1 : 1242-1243.

Smith H R, Rowe B, Gross R J, Fry N K, Scotland S M $1987 a$ Haemorrhagic colitis and Vero cytotoxin-producing Escherichia coli in England and Wales. Lancet 1: 1062-1064.

Smith H R, Scotland S M, Chart H, Rowe B $1987 b$ Vero cytotoxin production and presence of VT genes in strains of Escherichia coli and Shigella. FEMS Microbiology Letters 42: 173-177.

Smith H R et al. 1988 Vero cytotoxin production and presence of VT genes in Escherichia coli strains of animal origin. Journal of General Microbiology 134: 829-834

Smith H W, Green P, Parsell Z 1983 Vero cell toxins in Escherichia coli and related bacteria: transfer by phage and conjugation and toxic action in laboratory animals, chickens and pigs. Journal of General Microbiology 129: 3121-3137.

Spika J S, Parsons J E, Nordenberg D, Wells J G, Gunn R A, Blake P A 1986 Hemolytic uremic syndrome and diarrhea associated with Escherichia coli $0157: \mathrm{H7}$ in a day care center. Journal of Pediatrics 109 : 287-291.

Strockbine N A, Marques L R M, Newland J W, Smith H W, Holmes R K, O'Brien A D 1986 Two toxin-converting phages from Escherichia coli $0157:$ H7 strain 933 encode antigenically distinct toxins with similar biologic activities. Infection and Immunity 53: 135-140.

Taylor C M, White R H R, Winterborn M H, Rowe B 1986 Haemolytic-uraemic syndrome: clinical experience of an outbreak in the West Midlands. British Medical Journal 292: 1513-1516.

Tzipori S et al. 1986 The pathogenesis of hemorrhagic colitis caused by Escherichia coli $\mathrm{O} 157: \mathrm{H} 7$ in gnotobiotic piglets. Journal of Infectious Diseases 154: 712-716.

Wells J G et al. 1983 Laboratory investigation of hemorrhagic colitis outbreaks associated with a rare Escherichia coli serotype. Journal of Clinical Microbiology 18: 512-520.

Willshaw G A, Smith H R, Scotland S M, Field A M, Rowe B 1987 Heterogeneity of Escherichia coli phages encoding Vero cytotoxins : comparison of cloned sequences determining VT1 and VT2 and development of specific gene probes. Journal of General Microbiology 133 : 1309-1317.

Willshaw G A, Smith H R, Scotland S M, Rowe B 1985 Cloning of genes determining the production of Vero cytotoxin by Escherichia coli. Journal of General Microbiology 131 : 30473053.

Yutsudo T, Nakabayashi N, Hirayama T, Takeda Y 1987 Purification and some properties of a Vero toxin from Escherichia coli $\mathrm{O} 157: \mathrm{H} 7$ that is immunologically unrelated to Shiga toxin. Microbial Pathogenesis 3: 21-30. 
